\title{
Assessment of the level of care-burden in informal caregivers of patients with dementia
}

\begin{abstract}
S Abeywickrema, R Weerasundera, K Ranasinghe
\section{Background}

Worldwide, the incidence and prevalence of dementia is currently increasing. Dementia is associated with significant disability due to cognitive impairment, and sufferers often become dependent on their carers. Close family members often provide care for persons suffering from dementia, particularly in the developing world. This care-burden is associated with many consequences such as carer depression, elder abuse and premature placement of the patients in institutions. The consequences of care-burden have not been studied in depth in Sri Lanka. A better understanding of care-burden would be helpful to develop interventions to support carers as well as minimise the economic burden to the state.
\end{abstract}

\section{Objectives}

The objectives of this study were to describe the level of care-burden in carers of patients with dementia, and to explore possible associations between the care-burden and other variables such as sociodemographic factors and psychiatric morbidity.

\section{Method}

A total of 77 carers were included in the study. The locally adapted and translated Zarit Burden Interview (ZBI) was used to assess for care-burden, and participants were also clinically assessed for the presence of depression based on the Diagnostic and Statistical Manual - version IV (DSM IV) criteria for a major depressive episode. Socio-demographic details were gathered via a questionnaire.

\section{Conclusion}

Over one quarter of carers were experiencing a moderate to severe level of care-burden, and almost half reported mild to moderate care-burden. The level of burden increased significantly with increasing age, and a proportion of participants were also depressed. Further large scale, population based research is needed in Sri Lanka, to explore these associations further.

Key words: dementia, care-burden

SL J Psychiatry 2015; 6(1): 4-8

\section{Introduction}

Dementia is a syndrome of chronic and progressive nature, in which there is disturbance of multiple higher cortical functions, usually against a background of unimpaired consciousness (1). It is estimated that 24.3 million people world wide are affected with dementia, and 4.6 million new cases are diagnosed each year, most of whom live in the low and middle-income countries (2). Ageing is the most important non-modifiable risk factor for dementia. Approximately 5-8\% of individuals over the age of 65 years, and $20 \%$ of those over 80 years, are effected by this disease (3). Dementia, due to its chronic progressive nature and its inherent features of failing cognitive ability, leads to progressive disability, warranting a considerable degree of care. Given the trend towards an ageing population, the increasing incidence of dementia and the significant associated disability, increasing dependence on care givers is inevitable.

Currently in Sri Lanka, most persons with disability from any cause are cared for by family members, who serve as informal caregivers (4). An informal carer includes any person such as a family member, friend or a neighbour, who is giving regular, on-going assistance to another person without payment for the care given (5). They have no regular hours, often work around the clock and have significant subjective feeeling so for burden and are more susceptible to depression and anxiety than the normal population (5). About twice as many women are in the caregiving role compared to men (6).

Care-burden is defined as the extent to which the care givers feel that their emotional or physical health, social life and financial status have suffered as a result of caring for their relatives (7). A high level of care-burden is associated with depression and anxiety in the carer, reduced level of care for the patient, and premature placement of patients in long term care facilities (5). Sri Lankan studies regarding care-burden are minimal and a better understanding of care-burden in this country will help healthcare workers to identify such problems early and will also indicate ways in which to provide counselling and training for carers, in order to minimize carer depression and anxiety. Overall this will help ensure better care for the patient. The objectives of this study were to describe the level of care-burden in carers of patients with dementia, and to explore possible 
associations between the care-burden and other variables such as socio-demographic factors and psychiatric morbidity.

\section{Method}

Carers of patients with dementia attending the psychogeriatric out patient clinic at the National Hospital of Sri Lanka, (conducted by the National Institute of Mental Health) and outpatient clinics of Colombo South Teaching Hospital Sri Lanka, were recruited for the study over a period of 3 months. Carers of patients with dementia diagnosed for less than 6 months, guardian of patients who live in long term care facilities, and those who are unable to read and comprehend Sinhalese were excluded from the study. All those who met inclusion criteria, who gave written informed consent, were included in the study. Ethical clearance for the study was obtained from the Ethical Review Board of the Sri Jayewardenepura University.

Socio demographic data was collected via a questionnaire designed for that purpose. The care-burden was assessed by the use of the self-administered Zarit Burden Interview (ZBI) (5). This is a widely used self-administered scale for measuring the subjective care-burden in carers, which has been adapted and translated in to Sinhalese to be used in Sri Lanka (Written communication, the 10/66 Dementia Research Group-Sri Lanka, July 2011). This instrument consists of 22 items, each of which is scored from $0-4$. A total score of $0-20$ indicates 'little or no burden', 21-40 ‘mild to moderate burden’ 41-60 ‘moderate to severe burden' and 61-88 ‘severe burden' respectively. A total score of 24 or above indicates a significant risk of depression in the carer.

Depression in the carer was diagnosed via clinical interview as by a psychiatrist, based on DSM IV criteria. Data regarding the presence of behavioural and psychological symptoms of dementia (BPSD) among the care-recipients was gathered from the carers through a semi-structured interview. The last recorded mini mental state examination (MMSE) scores of the respective carerecipients were obtained from clinic notes.

Data was analysed using SPSS. Chisquare and Pearson correlation were carried out to explore associations between socio-demographic variables, BPSD, MMSE, carer depression and the level of care-burden.

\section{Results}

A total of 77 carers were included in the study. Most were female $(n=55,71.4 \%)$ and the mean age of the participants was 49 years, with $11.7 \%$ being over the age of 65 years. Of the carers, 83.1\% were currently living with their partners. More than half of the participants earned a monthly income below 20,000 rupees. The majority of carers were unemployed, and of those who had jobs, most were self-employed. With regard to relationship of the carer to the patient, $37.7 \%$ were daughters and $21.1 \%$ were wives.

Over one quarter of carers were experiencing a moderatesevere level of care-burden, and almost half reported mild-moderate care-burden (Table 1).

\begin{tabular}{|l|l|}
\hline \multicolumn{2}{|c|}{ Table 1. Levels of care-burden experienced by carers } \\
\begin{tabular}{|l|l|} 
ZBI score and level \\
of care-burden
\end{tabular} & $\begin{array}{l}\text { Percentage } \\
\text { (number) of } \\
\text { participants } \\
\text { effected }\end{array}$ \\
\hline 0-21: Little or no burden & $24.7 \%(n=19)$ \\
22-40: Mild to moderate burden & $42.9 \%(n=33)$ \\
41-60: Moderate to severe burden & $26.0 \%(n=20)$ \\
61-88: Severe burden & $6.5 \%(n=5)$ \\
\hline
\end{tabular}

Increasing age of the carer was significantly associated with a greater level of care-burden $(p=0.02)$, whereas increasing household income had a significant negative correlation with the level of care-burden ( $p=0.004$ ) (Table 2). Although a majority of care-recipients had features of BPSD, including wandering (71.4\%), aggression (63.6\%), features of paranoia (51.9\%) and disinhibited behaviour (48.1\%), there was no significant association between the presence of BPSD and care-burden. Likewise there was no significant association between the degree of cognitive impairment in the care-recipient, and the level of care-burden experienced. Of the carers, $3.9 \%(n=3)$ fulfilled the criteria for a major depressive episode. Surprisingly, there was no significant association between the level of care-burden and presence of depression in the carer $(\mathrm{p}=0.31)$.

\begin{tabular}{|c|c|}
\hline $\begin{array}{l}\text { Carer and care-recipient } \\
\text { characteristics }\end{array}$ & $\begin{array}{l}\text { Association } \\
\text { with level of } \\
\text { care-burden: } \\
P \text { value }\end{array}$ \\
\hline \multicolumn{2}{|l|}{$\begin{array}{l}\text { Socio-demographic } \\
\text { characteristics of carer: }\end{array}$} \\
\hline Gender & 0.13 \\
\hline Age & 0.02 \\
\hline Educational level & 0.23 \\
\hline Marital status & 0.39 \\
\hline Employment status & 0.46 \\
\hline \multicolumn{2}{|l|}{ Characteristics of care-recipient: } \\
\hline Presence of BPSD & 0.37 \\
\hline MMSE score & 0.12 \\
\hline Depression in the carer & 0.31 \\
\hline Lack of support from other sources & 0.04 \\
\hline
\end{tabular}




\section{Discussion}

The findings of this study show that $26 \%$ of carers were experiencing a moderate to severe level of care-burden. This is similar to findings reported from India, where care-burden has been reported to be $30 \%$ (8). It could be queried whether the prevalence of subjective care-burden would be lower in Eastern cultures, compared to the West - it may be argued that looking after ageing relatives might be appraised as less burdensome given the collectivistic nature of these societies. However studies done to explore this hypothesis so far have not confirmed this hypothesis (9).

In this study there was no significant difference between the care-burden reported by female and male carers; this is contrary to the findings in most international studies, which report a higher degree of burden among females $(10,11)$. Females are traditionally cast in the careproviding role in South Asia; therefore female carers may have been reluctant to state the true degree of burden, as 'looking after the elderly parent' is a culturally sensitive issue.

According to the results of this study, most carers (61\%) were over the age of 45 years, with $11.7 \%$ of the carers being over the age of 65 years - a major concern since the carers themselves are susceptible to a host of medical and psychological morbidities. It has been estimated that about half of informal carers are themselves elderly (6). In this study, the age of the carer was positively correlated with the care-burden, suggesting an increased subjective burden with advancing age. The available literature with regard to the age of the carer and the degree of burden felt is inconclusive. A recent study by the 10/66 Dementia group, of 673 participants carried out in multiple sites, report no relationship between carer strain and carer age (12). However other research has identified carer age as a predictor on dimensions such as 'guilt' in carer strain (13).

Our findings indicate that increasing monthly house hold income has a significant negative correlation with the carer-burden. This is similar to the findings of other international research - expressed financial distress has been shown to increase the care-burden $(14,15)$. It is likely that the availability of the support of paid carers and other informal support leads to a reduction of burden felt by the principal carer. The inability to arrange such support has been identified as a predictor of depression in the primary carer (16). This holds true even in countries where traditional family care is highly valued such as Japan (17). In this study, 71.4\% received external help in providing care for their ageing relative, while $27.3 \%$ did not have access to any such support. As expected, analysis revealed significant association between the availability of external support and the degree of burden felt.

There was no significant association between the employment status and the care-burden in this study.
Existing literature reveals mixed results, which could be due to the fact that being employed may have both positive and negative effects on the care-burden. Some researchers argue that these positive effects may outweigh the negative, and that being employed may reduce the overall level of burden (18). Other studies, however, report that employment does not have an effect on the overall level of burden $(19,20)$. Similarly, marital status did not impact significantly on the caregiver burden. This is supported by international findings, which indicates that being supported by a partner does not appear to reduce the burden in carers (12).

The last recorded MMSE score was taken as a measure of cognitive impairment of the care-recipients in this study. There was no significant association between the degree of cognitive impairment and the perceived careburden. Most studies report that while the degree of cognitive impairment does have an effect on the burden, it is the presence of behavioural and psychological symptoms of dementia that significantly worsens careburden experienced by the carer $(21,22)$. However, in contrast to the reported work, in this study the presence of BPSD did not establish a significant association with the degree of burden. The number of carers experiencing no BPSD in their patient may have been too small to give a significant difference in the analysis.

Rates of depression among carers of the demented elderly is reported to be higher than among noncaregivers (23). The prevalence of depression among care givers is estimated to be $41 \%-55 \%$, which contrasts sharply with the prevalence of $8 \%$ in non-caregivers (23). In our study 3.9\% $(n=3)$ carers fulfilled the criteria for a major depressive episode at the time of assessment. While all depressed carers reported a high degree of burden, statistical analysis did not reveal a significant association with the presence of depression and the level of care-burden. The limited number of depressed carers in this study may have influenced this finding.

\section{Limitations}

While the overall study sample size was adequate to describe the proportion of burdened carers, numbers in each sub-category was low. This is a limitation and may have influenced analysis of associations, as mentioned above. The data for this study was collected using the convenience sampling technique - this may have led to an over representation of care recipients with severe dementia and stressed carers when compared to population based sampling. And since the sample was obtained from two state hospitals situated in urban settings, the findings may not be generalizable to the entire population. The MMSE score was derived from records of the care-recipients, and therefore may not have represented the care recipients' current level of cognitive impairment. However since this study concerned the carers, and since the care-recipients were often unable 
or unwilling to attend the clinic, there were practical difficulties in obtaining the current MMSE. All efforts were made to minimize this error by taking the most recently ('last recorded') stated MMSE score from the records. Lastly, the assessment of BPSD was based on the carers' subjective statement, and may have been influenced by recall bias.

\section{Conclusions}

It is evident from this study that carers of patients with dementia in this country experience a significant level of care-burden, and this is significantly greater with increasing age of the carer. A proportion of carers were also depressed. The 10/66 Dementia research group states that although two-thirds of those with dementia live in the developing world, only one-tenth of research on dementia is conducted in these countries (24). In keeping with this, further research is needed in Sri Lanka, in order to identify the true magnitude of the problem, and to develop services and supports for carers of patients with dementia. Particular emphasis should be placed on large population based studies to analyse the care-burden in dementia and its determinants, in this country.

\section{Acknowledgements}

The authors extend their thanks to Dr. Jayan Mendis, for granting permission to carry out the study in the psychogeriatric clinic, conducted by the NIMH held at NHSL, to Dr. Pushpa Ranasinghe, the consultant in charge of the said clinic, and to Dr. Manoja Kulathunge for permission to gather data when the study population was extended to the Colombo South Teaching Hospital. The authors also extend their sincere gratitude to Dr. Athula Sumathipala and Dr. Sisira Siribaddana, for permission to use the translated and adapted version of the Zarit Burden Interview, and to Prof. S. Sivayogan and Dr. Gamini Wijayasiri for their statistical advice.

\section{Declaration of interest}

None declared

S Abeywickrema, District General Hospital, Nawalapitiya, Sri Lanka

R Weerasundera, Royal Darwin Hospital, Darwin, Australia

K Ranasinghe, National Institute of Mental Health, Angoda, Sri Lanka

Corresponding author: S Abeywickrama

E-mail: sambeywick@yahoo.com

\section{References}

1. The ICD 10 classification of Mental and Behavioural Disorders: clinical descriptions and diagnostic guidelines. Geneva: World Health Organization; 1992.

2. Ferri CP, Prince M, Brayne C, et al. Global prevalence of dementia: a Delphi consensus study. Lancet 2005; 366(9503): 2112-7.

3. World Health Organization. The world health report. Geneva: WHO 2001.

4. Ministry of Social Welfare. National Policy for Disability in Sri Lanka. Colombo: Ministry of Social Welfare; 2003.

5. Parks SM, Novielli KD. A practical guide to caring for caregivers. Am Fam Physician 2000; 62(12): 2613-20.

6. Gelder MG. Harrison P. Cowen P. Shorter Oxford Textbook of Psychiatry. 5th ed. Oxford: Oxford University Press; 2006.

7. Zarit SH, Reever KE, Bach-Peterson J. Relatives of the impaired elderly: correlates of feelings of burden. Gerontologist 1980; 20(6): 649-55.

8. Emmatty LM, Ranbir S, Bhatti S, et al. The experience of burden in India. Dementia 2006; 5(2): 223-32.

9. Knight BG, Sayegh P. Cultural values and caregiving: the updated sociocultural stress and coping model. J Gerontol B Psychol Sci Soc Sci. 2009; 65B(1): 5-13.

10. Gallicchio L, Siddiqi N, Langenberg P, Baumgarten M. Gender differences in burden and depression among informal care givers of demented elders in the community. Int J Geriatr Psychiatry 2002; 17(2): 154-63.

11. Schulz R, Martire LM. Family caregiving of persons with dementia-prevalence, health effects and support strategies. Am J Geriatr Psychiatry 2004; 12(3): 240-9.

12. Prince $M$, Brodaty $H$, Uwakwe $R$, et al. Strain and its correlates among carers of people with dementia in lowincome and middle income countries. A 10/66 Dementia Research Group population-based survey. Int J Geriatr Psychiatry 2012; 27(7): 670-82.

13. Springate BA, Tremont G. Dimensions of caregiver burden in Dementia: impact of demographic, mood and care recipient variables. Am J Geriatr Psychiatry 2014; 22(3): 294-300.

14. Schneider J, Murray J, Banerjee S, et al. EUROCARE: a cross sectional study of co-resident spouse carers for people with Alzheimer's Disease - factors associated with care burden. Int J Geriatr Psychiatry 1999; 14(8): 651-61.

15. Andren S, Elmstahl S. Relationship between income, subjective health and care giver burden of care givers of people with dementia in group living care: A cross sectional community based study. Int J Nurs Stud 2007; 44(3): 435-46.

16. Chang BL, Brecht M, Carter PA, et al. Predictors of social support and caregiver outcomes. Women Health 2001; 33(1-2): 39-61.

17. Kumamato K, Arai Y, Zarit SH. Use of home care services effectively reduces feelings of burden in family care givers of disabled elderly in Japan: preliminary results. Int $\mathrm{J}$ Geriatr Psychiatry 2006; 21(2): 163-70.

18. Scharlach AE. Caregiving and Employment: competing or complementary roles? Gerontologist 1994; 34(3): 378-85. 
19. Edwards AB, Zarit SH, Stephens MAP, et al. Employed family caregivers of the cognitively impaired elderly: an examination of the role strain and depressive symptoms. Aging Ment Health 2002; 6(1): 55-61.

20. Herbert R, Bravo G, Preville M. Reliability, validity and reference values of the Zarit Burden Interview for assessing informal caregivers of community - dwelling older persons with dementia. Canadian J aging 2000; 19(4): 494-507.

21. Germain S, Adam S, Oliver C, et al. Does cognitive impairment influence burden in caregivers of patients with
Alzheimer's disease? J Alzheimers Dis 2009; 17(1): 105-14.

22. Black W, Almeida OP. A systematic review of the association between the Behavioural and Psychological Symptoms of Dementia and burden of care. Int Psychogeriatr 2004; 16(3): 295-315.

23. Redinbaugh EM, MacCallum RC, Kiecolt-Glaser JK. Recurrent syndromal depression in caregivers. Psychol Aging. 1995; 10(3): 358-68.

24. Prince M. Dementia in developing countries. A consensus statement from the 10/66 Dementia Group. Int J Geriatr Psychiatry 2000; 15(1): 14-20. 